\title{
Plato's Philebus
}

Sean P. O'Connell

Fordham University

In earlier dialogues, such as the Phaedo, Socrates concerns himself with the life that frees the soul from the corporeal, while in the Philebus he inquires into the composition of the good life. Are both lives the same? Freedom from the corporeal is of central importance to Socrates because the corporeal is subject to change and decay. As such, it is not that which most truly is, and therefore is in a sense illusory. If one is to become free from the corporeal, one must turn away from the corporeal by engaging in the search for truth, for that which most truly is. In the life of philosophy this enterprise is undertaken. The art of philosophizing is the art of dying, of dying to the corporeal.

The Phaedo advocates such a life, and at the same time, it along with other earlier dialogues, seems to associate pleasure and pain with the corporeal. In the search for truth, one moves beyond the bodily experience of pleasure and pain to the immortality resulting from action and dialectic. This seems perplexing, for one ordinarily would think that pleasure ought to be an element found in the good life. What precisely is to be done about pleasure? Is it to be totally excluded from the life of philosophy? Is it to be excluded from the good life? Is excluding it from the one the same as excluding it from the other? We can effectively answer these questions by turning to the Philebus, for there we discover that Plato's treatment of pleasure and pain is not so simple--or simplistic-as might initially be supposed.

If we were to compare the Philebus with an earlier dialogue such as the Phaedo, we might initially be tempted to claim that the latter is the more "beautiful" of the two and therefore the more "pleasing." But for Plato, it is the Philebus with its appeal to dialectic, its slight use of imagery, and its almost total abandonment of myth which is truly the more appealing. Why? Because it recognizes explicitly what the Phaedo recognizes only implicitly through its aesthetic appeal to the senses, namely, that the good life 
is a life which must include pleasure, but pleasure of a certain kind. The good life is one in which pleasure necessarily accompanies the art of dialectic and the special kind of contemplation granted only to few, which will be described later. Pleasure necessarily accompanies these because we are human. We are not gods! We are not pure reason which can stand independently of pleasure because our corporeal nature does not allow it. So long as the soul is encased in the body, even it cannot escape pleasure.

But it is possible for the soul to be rightly captive only to that pleasure which accompanies the art that moves beyond our human estate. Why in the Phaedo does Socrates reject the life of pleasure? He rejects it because he considers it strictly in 1 ts mixed form, as numerous passages illustrate:

But if she be defiled and impure when she leaves the body, from being ever with it, and serving it - . and from being besotted by it and by its desires and pleasures, so that she thinks nothing true but what is bodily. . . if she has learned to hate and tremble at, and fly from what is dark and invisible to the eye, and intelligible and apprehended by philosophy--do you think that a soul which is in that state will be pure and without alloy at her departure?

What distinguishes the Philebus is that Socrates explicitly recognizes the importance of a true pleasure which he cannot escape if he is to take the path which points beyond his mortal state and the pleasures which accompany it. What makes the Philebus interesting is that the human condition, as socrates so forcefully presents it, has as its complement and as the basis of its understanding the ontological structure of the universe. In short, the philosophic life, the good life, is nothing less than a mirror reflecting the interplay between Limit and Limitlessness. The Limitless is the indeterminate, infinite many expanding in both directions. Its power meets with, mixes with, the power of Limit, which is the one, that which imposes determinateness through the introduction of ratio. It is this which explains the structure of reality and the order found therein. The good life mirrors this because it involves the limiting of limitless pleasure through the application of reason.

our task is twofold. First, we must examine the Philebus to come to an understanding of the nature of the good life and the role pleasure plays in that iffe. Secondly, through the development of our first objective, we must consider more carefully both whether there is a parallel between the good life and the structure of reality and in what that parallel consists. 
Wel1, Philebus says that the good for all animate beings consists in enjoyment, pleasure, delight, and whatever can be classed as consonant therewith, whereas our contention is that the good is not that, but that thought, intelligence, memory, and things akin to these, right opinion and true reasoning, prove better and more valuable that pleasure for all such beings as can participate in them, and that for all these, whether now living or yet to be born, nothing in the world is more profitable than so to participate...

In these early lines of the Philebus, the two fundamental positions to be explored are laid out. Later in the dialogue (60a), Socrates elaborates on the position of Philebus, and defended by Protarchus, that pleasure is the right aim of all living things, and that it ought, therefore, to be sought. Philebus does not claim that all creatures do in fact seek it, but he does hold that 'good' and 'pleasant' have the same meaning. Thus, the Hedonism which he advocates is extreme, allowing no value to anything except pleasure. Socrates' position, on the other hand, is not an extreme one." He suggests that, " thoughtfulness in deciding how to act the apprehending of what is intelligible only the power of memory, right opinion and true calculations " are better than pleasure. but better only for those capable of them." He does not exclude the possibility, however, that pleasure might have some intrinsic value.

Notice, however, what happens with these classifications of the good and the pleasant. With the claim that pleasure is the highest good the discussion actually centers on what is the highest good, s and through Socrates' addendum of a criterion of capability together with his agreement with Protarchus that they are only going to consider a condition of the soul capable of providing human happiness," we find that the discussion is going to focus on the highest good for the human. Moreover, Socrates indicates further that the dialogue will not consist merely in attempts to defend either his own position or that of Protarchus when he suggests that there may be some third alternative that will win the argument (11d-e).

With these preliminary considerations complete, Socrates begins to guestion Protarchus about the unity of pleasure. Protarchus argues that it is true that pleasure can arise from differing sources, but that this does not mean pleasure differs from itself. Socrates counters with an examination of figure and says that, as a class, all figure is one, while, within the class, some figures are absolutely opposite to each other (12e). But Protarchus is not willing to readily 
surrender his opinion concerning the unity of pleasure. It is not until Socrates contends that there are many kinds of knowledge as well that protarchus is brought to submission (13b-14a). Protarchus is pleased to find that Socrates' candidate is in the same position as his own.'

However, R. Hackforth points out that Protarchus could have rejected Socrates' analogy on the grounds that there is no counterpart in pleasure, as in figure, if we take pleasant to mean pleasant feeling per se. There is a counterpart to pleasure only if we take pleasure to mean both the complex and the source of feeling. Socrates' argument implies this second sense throughout the present section. Why does Plato not allow for Protarchus' suggestion? Hackforth's answer is that Plato believed there to be genuine qualitative differences between pleasure-feelings. He believed that the feeling aroused by listening to great music, for instance, is qualitatively different from that aroused by eating cake, though he could not prove it.: Furthermore, he probably felt it unreasonable to expect him to prove it, since the isolated pleasure-feeling is nothing more than an abstraction, for ". . . what really occurs is always 'my pleasure in this', an indivisible whole though divisible in analysis." We shall see later the importance of this notion of pleasure being always related to that which gives the pleasure when discussing true and false pleasures. But what is most interesting at this point is the openning provided by this examination of pleasure for a discussion of the one and the many.

Jacob Klein makes the observation that the dialogue initially is concerned with things familiar to us--it is concerned with our lives in the world of experience. With the introduction of the topic of the one and the many, the conversation is lifted to the level of "allembracing universality." " Conversation concerning pleasure and knowledge is disregarded for the moment. This jump from common experience to a higher level is one which occurs several times in the dialogue. Why does this happen? Klein suggests that socrates is searching for the ultimate sources of what is close to but unquestioned by us." I will suggest that, indeed. Socrates is attmepting to construct a link between the good life of man and the structure of reality. But Klein does not see this link in the same way as $I$, since we differ on the parallel to be drawn between the structure of the good life and the structure of reality. Eurther development of this must be delayed for the moment, however.

Returning to the question of the one and the many. we see that Socrates finds nothing disturbing about the supposition that one is many and that many are one when it refers only to the visible realm. His difficulty arises in considering the intelligibles, or the eide of 
things, for each of these is one and unique and can be encountered only in speech. ${ }^{12}$ How can they retain their unity while being split up amongst an indefinite number of particulars? Socrates holds that the only way to answer this question is not by exploiting it polemically but rather by applying to it the dialectical method. It is necessary, for example, that we take note of the Pythagorean treatment of Limit and the Unlimited: we must see how each generic unity has within itself a definite number of "kinds" that mediate between itself and the infinity of particulars into which finally it vanishes." Between the original One and the original Many, there are many "Ones," and the philosopher's task is to discover both what these intermediates are and how many they are. ${ }^{14}$ This can be done through the method of division. In other words, the philosopher must look for one eidos and then for two, if there are two, or for some other number if there are more. He must treat each of the eide the same, subdividing them "s". . until we come to see not merely that the one that we started with is a one and an unlimited many, but also just how many it is." (16d) This being done, it is then possible to dismiss the Idea of infinity. ${ }^{16}$

Socrates provides us with three examples of the method he is describing. The examples of sound in speech and musical sound show the mediated passage from a one to an indefinite plurality, while the example of letters in the alphabet illustrates the reverse procedure." However, it is not to be thought that the method Socrates is proposing is an easy one, for he is careful to stress the objective character of classification. The classes ought not be too many or too few; they must correspond to the forms actually existing. "i It is the difficulty of the procedure which will cause Protarchus to object and which will result in a subsequent shift in the dialogue.

Before this transition occurs there is a curious little section in which Philebus enters the conversation. He asks why Socrates embarked on this discussion of the one and the many and shows signs of intellectual curiosity. It is interesting to note that Protarchus, the defender of pleasure, provides the answer, namely, that Socrates was trying to determine whether or not there are eide of pleasure and of thoughtfulness that are distributed among the various beings that come to be and perish, among beings who live lives in pleasure and in thought. " The very fact that these two interlocutors who defend the primacy of pleasure to the detriment of thoughtfulness are caught up in a discussion that attempts intellectually to settle on the nature of the good life is ironic, and that irony is never so pointed as in this passage where the processes of intellect and reason are defended by protarchus as the means of establishing what is the good life. 
However, Protarchus' implicit defense of the thoughtful iffe soon dies away as he claims that the method Socrates proposes, a method which is the gift of the gods, is too difficult. He does not feel capable of classifying all of the various kinds of pleasure and asks Socrates either to make the classification himself or to find another method. This opens the question of whether there is some third which is the good, for if there is, then pleasure could not win the victory because it could not be identical with the good, and there would be no need to investigate further (20b-c).

In the discussion which follows, three insights are developed. First, it is discovered that the cood and only the Good is gelf-sufficient (20d). Secondly, in trying to separate the life of pleasure from the thoughtful life to consider each independently, taking from each all qualities which belong to the other, it is found that neither life is self-sufficient, desirable, or good in itself. Without thought, knowledge, memory and opinion, the pleasant life cannot be enjoyed, and without pleasure, the thoughtful life is sterile (2ld-e). Thirdly, from the two observations above, the conclusion is drawn that the good life, the kind of life that everyone would choose, is one that is composed of a proper mixture of pleasure and thoughtfulness. Neither pleasure nor thoughtfulness alone can be assigned to the good life (22a-b).

There are several interesting observations that can be made about the discussion. First, it is quite important to stress just how much thoughtfulness depends upon pleasure and pleasure depends upon thoughtfulness in the good life. The pleasant life in itself is not really pleasant, and the thoughtful life in itself is not really reasonable. We see this is so because thoughtfulness itself not only gives pleasure but at the same time gives the power of appreciating or experiencing pleasure. Moreover, it is unreasonable to want a life of pure thoughtfulness devoid of pleasure because the human condition by its very constitution requires that thoughtfulness be experienced as pleasurable. Second, we should notice that, while socrates' refutation of the pleasant life as the good life is based upon the notion of choice worthiness, it is clear that it, along with the life of thoughtfulness, is rejected with respect to the criterion of adequacy and perfection as well. Third, it ought to be noted that the refutation of Philebus' contention constitutes only a small portion of the dialogue. The major part of the dialogue consists in trying to show that while pleasure is necessary for happiness it is less valuable than intellectual activity. In order to demonstrate this, it will be necessary for socrates to return to a discrimination of the various kinds of pleasure. He must distinguish between true and false pleasures and between pure and mixed pleasures. Finally, it would be noted 
that Socrates here shifts from his original contention that reason is the cause of that Goodness found in the mixed life to the position that reason is nearer and more akin than is pleasure to that which makes a life both good and desirable. The purpose for this change in position becomes clear later in the dialogue (65a-b) when we discover that neither of the components of the good life make it what it is. Rather, we shall find that the characters of Measure, Proportion, and Symmetry inherent in the composition of the good life are the source of its goodness. We shall find that even the pleasures present in the good life will have these characters, but will have them only because, and to the degree that, reason, through its control, imparts and maintains them. ${ }^{\circ}$ Hackforth tells us that we shall see that,". . . the cause of the goodness in the Mixed Life is twofold; ... the Formal Cause is... the right quantitative relation between the various kinds of intellectual activity and pleasurable experience which are admitted; while the Efficient Cause is Reason; immediately, the controlling reason of the individual man, but ultimately the Cosmic Reason, on which the individual's reason is declared to be dependent. . " 21

\section{I I}

The stage is set for a discussion which will ultimately lead to a disclosure of Cosmic Reason as the causative and controlling factor in the universe, a discussion which will show human reason's superiority over pleasure. This new discussion will involve a division of the universe into what Klein calls four tribes.22 These four tribes consist in the Unlimited and limit, which are the two constituents revealed by God, next that which arises out of the mixture of them both, and finally the cause of the mixing of these two things with one another $(23 c-d)$. Socrates starts with a desciription of the Unlimited. Eirst, he says that it is in a sense a many. The Unlimited is concerned with boundless pairs. with "the more" and "the less." If a term were absolutely set, it would mean the end of their existence, for such things as "hotter and colder" never stop where they are but continue always to go to a point further. Definite quantity implies a cessation of movement (24-b). In other words, the Unlimited is indeterminate and ceases to be the Unlimited when it is fixed by a determined number. But it is at the same time a duality which has the seed of a single nature. It is not the more or the less which is the Unlimited; it is the more as well as the less which is the Unlimited. 23

Turning now to the second tribe, we find that it consists of those things that do not admit of the terms found in the first tribe. Limit, rather, admits of the 
opposite terms, ". . terms like 'equal' and 'equality' in the first place and then 'double' and any term expressing a ratio of one number to another, or one unit of measurement to another.." (25a-b). But Socrates goes on to postulate a family of the Limit, a family paralleling the family of "hotter and colder," "drier and wetter," etc., belonging to the tribe of the Limit (25c-d). This family is the limited and consists in that which brings proportion and ends variability between opposites through the introduction of number. In short, it consists of ratios.

The distinction between Limit and Limited is that the Limited is that which has limit. ${ }^{24}$ The full power of this distinction comes out in an examination of the third tribe, where, indeed, the Limited makes its full appearance. Socrates tells us that the source of all beautiful things is to be found in the third tribe, in the mixture of the Unlimited with the Limited (261-b). What seems actually to be taking place in the third tribe is that the Limitless, or the indeterminate dyad, and the Limit, or the One, are exerting their respective "powers" upon one another. Through this exertion of power, these two arche interact in the following manner. The indeterminate dyad duplicates or copies the One. In other words, it produces two entities or eide. . It continues this process indefinitely. (Aristotle tells us that plato considered the indeterminate dyad to be the doubling power which is the ultimate source of definite manyness, the source of "numbers" both in the realm of the eide and in our realm as well.) 28

Earlier, when Socrates first mentions the two arche as the gift of Prometheus and tells us that in every case a definite number of eide must be found, he dismisses consideration of the application of the character of Unlimitedness until this number has been discovered (16d). But at the point in the dialogue we are now considering $(25-26)$ he does not so dismiss Unlimitedness because he is considering the world in which we live, and the Limitless is necessarily an element in the world.26 I think this is important for we shall see that pleasure is to be identified with the Limitless. By saying that the Limitless cannot be banished from our world, we are saying that pleasure cannot be banished from our individual lives. In this world, Limit, or the one, acts upon the indeterminate dyad, changing it into a determinate one. In other words, it acts upon the two constantly changing terms of the dyad transforming them into two stationary and determinate ones and continues this process thereby producing a multitude of "ratios." These "ratios," then, which constitute the Limited, are what Socrates calls the offspring of Limit."2 From this, we can gather that, while the limited is a member of the family of limit, it belongs to the third tribe. The 
closeness of these two suggests the primary position of Limit with respect to the mixture while at the same time not dismissing Limitlessness as superfluous. We should note that the limited as part of the third tribe represents mixture of a special kind. It represents

those mathematical partnerships that can give to parts of the world we live in a certain rightness, remove the excess and indefiniteness, and produce balance and right measure. Such mathematical partnerships engender, for example, health, establish the entire genuine art of music, bring about the temperate seasons and all the bounties of the soul."

The fourth tribe consists of that which causes things to happen in the physical universe. This tribe makes things to be what they are and is in general responsible for all change and motion. This tribe is the cause, it is the nous working throughout the entire physical universe. As such, it is animate being. But the change which takes place in the universe has about it a certain uniformity and regularity which is expressible in laws or formulae. Therefore, this cause must be rational soul or mind, which is the reason we can call it nous. It is rational soul which performs the dual function of causing change and causing orderliness and regularity. ${ }^{2}$

Hackforth points out that if such an Intelligence exists as cause, there will be grounds for arguing that man's intelligence, as part of the mixed life of the individual, has a closer relation to the cause of the good life's goodness than does pleasure. He goes on to say that it is not our intelligence which makes the mixed life good, but rather nous acting as an external efficient cause imposing Limit on the Unlimited gives the good life its sumnetria."

Jacob Klein, on the other hand, paints quite a different picture. He points out that Socrates was reluctant to admit the fourth tribe into consideration at all and questions if there is any reason for postulating it. He argues that it is the common power of the Limitless and the Limit that is the cause of the mixture, as well as of that which is engendered in it, and that socrates did not show that the cause which fabricates the other three tribes is distinct from them. He asks how it could be that two ultimate sources could be caused by an other, since to say this would be to say that the Limitless and the Limit are not what they are. In effect, Klein does not think that Socrates actually admitted this fourth tribe as distinct from the other three." But I would like to offer several objections to Klein's position and then suggest somewhat of a middle course between Klein's and Hackforth's respective stands, a course that I believe 
will shed some light on the nature of the good life for Socrates.

To Klein's objection that Socrates admits the fourth tribe while fearing that he may be making a mistake, Marsillio Ficino's observation that Socrates promised only to enumerate those things existent in the universe and that there can only be three such things forms an apt reply. Ficino holds that Socrates introduced the fourth tribe because it would be ridiculous to discuss the three tribes within the universe without referring to the cause which is above the universe.'2 In other words, Socrates hesitated not because there was no independent cause but because he had originally agreed to consider solely the three tribes within the universe.

A second objection comes from Damascius who says that there can only be a symbolical value given to the distinction between the two principles of limit and Limitlessness because there is no such distinction, no separateness of any sort, on the purely intelligible plane. He summarizes as follows: "In a way, therefore, there is not even duality younder, but there is an unknowable. One after the Unknowable, then another unknowable principle of plurality; then, in accordance with the current view among philosophers, the intelligible world." If If his view is correct, then the notion of cause is certainly more primary than the notions of Limitlessness and Limit. Still a third objection might simply be Socrates' claim that one must regard it as necessary that a cause be postulated for all things that come to be, as the cause is more primary than the caused $(26 e-27 a)$.

However, to do justice to Klein we must note that he does not wish to dismiss the cause but rather to dismiss a cause which exists outside of limit and Limitlessness. On the contrary, Hackforth downplays individual nous in favor of the cosmic nous. Klein, as we shall see, will insist that the individual's nous is responsible for the happy life. I should like to suggest that both are to a certain degree correct, and to a certain degree mistaken. It is the individual noug which is, as Klein says, responsible for the kind of mixture which is made to produce the life which combines thoughtfulness and pleasure." The invividual nous is able to act as it does, however, only because there is an overarching structure of reality which it imitates. Whether or not the cosmic nous is to be found outside of the power of Limitlessness and Limit is irrelevant--recognition of the role of the fourth tribe is what is central. The beauty, truth, and due measure found in the good life must reflect the beauty, truth, and due measure found in the universe, or else the good life would not be the good life since it would not be reflective of that which is ultimately good. The individual nous must act to cause the proper mix- 
ture, but if there is an individual nous, which Klein says there is, acting as it acts, then there must be a cosmic nous which it imitates. But we are anticipating many of the clarifications yet to be made. Let us briefly summarize what has been said in this section of the dialogue and then return to socrates' battle for "second prize."

We found that the reality of the Unlimited is rooted in the fact that it functions as the material used in the forming activity of the Limit, while the reality of the Limit is rooted in the fact that it gives form to the formless. The reality of the Mixed is centered in the fact that the Unlimited and the Limited, while capable of being separated through abstraction, nonetheless have been united and given in the Mixed."s Finally, the postulation of the reality of the cause as a fourth tribe can be based ". . . In the fact that the process of development, through which this alone could and can happen, is not merely known as a logical cause of an event, but is initiated as an impact, the actuality of which is put outside the whole action of causally connected events at which we can arrive by a mere logical procedure and by tracing back the whole process."

\section{IV}

Socrates: "Come along now, what is our next point, and what was our purpose in getting to where we have got? Wasn't it that we were trying to find out whether the second prize would go to pleasure or to intelligence?" (27c). Immediately, Socrates brings us back to the more concrete concerns of the dialogue. He starts once again to consider the nature of pleasure and aligns it with the Limitless, with that which admits of "the more" and "the less" (27e). It is interesting to note that it is Philebus who agrees with this, saying that pleasure must admit of "the more" and be unlimited both in quantity and degree if it is to be the best (27e). It is ironic, I think, that this should be the justification for classing pleasure along with the Limitless, as the Limitiess is indeterminate and in need of order; but it is Philebus, the symbol of pleasure, who thoughtlessly assigns pleasure its realm. However, the designation may be correct while the reasons may be wrong. That this is the case receives some verification through Socrates' observation that pain likewise must find its home in the same realm (28a).

Pleasure and pain, then, are a limitless pair. Thus, there can be, properly speaking, no eide of pleasure, for eide come about only as the result of the implementation of ratio. This provides a second, hidden reason why Socrates did not attempt earlier to divide pleasure into its eide but rather turned immediately towards the search for some third."' 
Turning now to consider to which tribe nous belongs, we shall see that Socrates offers a cosmological argument for placing it in the fourth tribe. Klein dismisses this account as a playful one," but perhaps this section has a good deal more to say. Socrates and Protarchus begin by agreeing that the cosmos is ordered and that they can discern certain constituents of the corporeal nature of all animals, these being fire, water, earth, and air (28d-29a). Yet, in individuals these constituents, according to socrates, are found in only a very limited degree and are, moreover, lacking in quality and power when compared to their real nature. Using fire as an example, Socrates shows us that the constituents found in us are dependent upon these same constituents found in their purer form in the universe $(29 b-c)$.

Now, the constituents, when taken as a collective unity, are given the name body; our body, therefore, is dependent upon the universe's body for its coming to be. Moreover, Socrates tells us that our body has a soul and that the only way it could have derived a soul is from the soul of the universe (29d-30a). This seems to support the position that the individual and the life of the individual ought to reflect the structure of reality. Socrates goes on to say that there is an ordering principle to the universe which has a right to the names of wisdom and reason (30c). Wisdom and reason, then, belong to the fourth tribe (30d-e). Socrates: "Then let us have these points in mind about the pair of them, namely that reason was found akin to cause and belonging, we may say, to that kind, whereas pleasure is itself unlimited and belongs to the kind that does not and never will contain within itself and derived from itself either beginning, or middle, or end." (31a). We might go so far here as to award the second prize to reason, for, as we saw earlier, cause is more primary than that which comes to be, whereas pleasure, as aligned with the indeterminate, is continually coming to be.

Yet, Socrates wants to embark on an investigation of reason and pleasure to determine where each is found and what happens to make them come about when they do occur. Socrates begins again with pleasure (31b). He first notes that there are some pleasures which involve the restoration of equilibrium to the physical organism, that restoration resulting in a cessation of pain. The second type of pleasures and pains mentioned are those involving an anticipation of the first sort. Feelings of pleasure accompany expectations of pleasant experience while feelings of anxiety accompany expectations of future pains. Now the anticipation of future pleasure can exist alongside the present experience of actual pain. This is one type of what Socrates shall call mixed pleasures." ${ }^{3}$ Socrates' examination of these mixed anticipatory pleasures brings up the point that 
desire does not belong to the body since every creature's energy is directed against the body's present state and towards a more adequate state (35c). The desire for something opposed to experience, moreover, proves the existence of memory (35c). "Our discussion then, inasmuch as it has proved that memory is what leads us on to the object of our desire, has made it plain that it is to the soul that all impulse and desire, and indeed the determining principle of the whole creature belong" (35d).

Thus, once again pleasure, because it is dependent, plays a subsidiary role. But socrates also mentions a third state in which one neither feels pleasure nor pain. The one who can live a life of thoughtfulness can live in this state, he says, and he further comments that it is the most god-like (32e-33b). This certainly seems at odds with what was said earlier concerning a life devoid of pleasure as not being desirable any more than a life devoid of reason, memory, etc. The answer to this is, I think, twofold and has already been mentioned. First, we are not gods and are therefore susceptible to the structure of this world. Secondly, the two types of pleasure mentioned above are mixed pleasures. But Socrates will, as we shall see, propose that there exist certain pure pleasures which are admissible to the good life.

Through his observation that one can experience pain in the body and at the same time experience pleasure in the soul through an anticipation of relief from that pain, Socrates raises the question of whether pleasures and pains can be considered to be true or false $(36 a-c)$. Protarchus' position is basically that, no matter what one's condition, one cannot suppose that he is pleased or pained unless he really is pleased or pained, and, similarly, whether a person is holding an opinion rightly or wrongly, he is still holding an opinion $(37 a-b)$. Socrates counters by saying that we nonetheless consider opinions to be distinguished with regard to their truth and falsity and asks how Protarchus can hold that the same ought not be held with respect to pleasures.

In order to show that pleasure indeed is no more exempt from the claims of truth and falsity than opinion, Socrates introduces three types of false pleasure. The first type is that which accompanies false belief." With respect to opinion, we find that falsehood and truth supervene causing the opinion to be of a certain sort, either true or false; and so do pleasure and pain, just as opinions, have similar qualities. Accordingly, it must be agreed that pleasure can be either good or bad and can also be incorrect or correct with respect to the object that is arousing the feeling. In other words, it must be admitted that it is possible to experience pleasure when the opinion on which that pleasure is based is false (37d-e). 
Protarchus, however, continues to stubbornly hold that, while the opinion is false, the pleasure cannot be so classed (38a). Socrates finally attempts to resolve the issue by using the image of a scribe who writes certain things which are true and certain things which are false in the soul and thereby produces true and false opinions respectively. Likewise, pictures of false pleasures are painted on the minds of the evil $(39 a, 40 b-c)$.

The point being made in considering this first false pleasure is that it is not true to fact to consider the pleasure-feeling in abstraction from 1 ts objective reference just as it is not true to fact to consider the act of opining or judging in abstraction from its object. " 1 When one says that he takes pleasure in a certain belief, he does not mean that he takes pleasure in his believing but rather that he takes pleasure in the proposition believed." 2

The second kind of false pleasure is that which results from the overestimation or underestimation of a pleasure due to the fact that one is comparing it to a pain. ${ }^{4}$ Both pleasure and pain can be experienced at the same time in the mind, but one of them may have its source in the body while the other has its source only in the mind. Because the feeling "supplied" by the body is "close to hand" while that in the mind is at a "distance," the former is liable to exaggeration while the latter is subject to being underrated. The real magnitude of either feeling could be found only if the iliusory part were subtracted, which is impossible. This second type of falsity is due to the unlimited character of pleasure and pain, for, if precise mathematical determination could be introduced, mistakes with respect to magnitude would not be made."

The third type of false pleasure which socrates mentions is actually a misclassification of the neutral state as either the pleasant or the painful state. There are times when neither pleasure nor pain are felt, but one may claim mistakenly that he is experiencing either pleasure or pain simply because there is ambiguity in his feeling nothing. "s Noting this third type of false pleasure brings to socrates mind those who do not believe that pleasure exists at all but rather hold that what is called pleasure is nothing more than release from pain $(44 b-c)$. They open the way to a discussion of the various forms of mixed pleasure, that is, of pleasure mixed with pain. This discussion is important for it provides the background to an introduction to true pleasures.

It is in the profligate rather than the temperate life that the most extreme pleasures are to be found. Yet, when one is mastered by these extreme pleasures, he becomes insane. Thus, the greatest pains accompany the most extreme pleasures, and the most extreme pleasures and pains occur when the body and soul are bad 
rather than good. Socrates goes on to say that they ought to choose examples of such pleasures and consider what characteristic it is that makes them called greatest in magnitude. The pleasures he proposes to investigate are those which he says were refered to by the people who claimed that pleasures are only releases from pain. Protarchus calls these pleasures mixed. Socrates agrees and proceeds to give the various possibilities of mixture $(45 d-46 e)$. Socrates:

Well, some of the mixtures concern the body and are found in the body alone, while others are found in the soul and belong to the soul alone, and thirdly we shall discover cases of pains being mixed with pleasures that involve both soul and body, where the total experience is sometimes called pleasure, sometimes pain $(46 \mathrm{~b}-\mathrm{c})$.

The dialogue next moves naturally to a consideration of true pleasures and shows that these are unmixed, for, while they are not the greatest, they are the purest of pleasures. In 51b Protarchus identifies unmixed pleasures with true pleasures indirectly simply by asking Socrates which pleasures ought to be considered by them as true. Socrates lists five different kinds of true pleasure, four of which are experienced through sensation while one involves that which cannot be sensed. The first four types of pleasure he lists have their source in beautiful figure, beautiful colour, clear sound, and many odours while the fifth kind of pleasure has its source in the known as knowable, in that which is accessible to human beings wi thout accompaniment of a hunger for learning. "*

What one immediately notices about all five of these pleasures is that they are unmixed with pain. Such things as straight lines, simple curves, colour, things which are not mere imitations of the sensory world, have as an intrinsic quality beauty, beauty which is not dependent upon contrast with something less beautiful or ugly in order to be recognized or called beautiful. The beauty they have is special, for it is the beauty of a differentiated unity, and of a differentiated unity with only the very minimum of differentiation." This view of their beauty is in perfect accord with the Greek ". . . 'principle that beauty consists in the imaginative or sensuous expression of unity in variety." 140 Thus, we recognize beauty through the thoughtful consideration of these things, but the pleasure we feel is the result of our encasement in the human body.

Socrates has by this point noted the difference between true and false pleasures, between mixed and unmixed pleasure. Hackforth blithely tells us that Socrates uses the two pairs of terms interchangeably but must now nevertheless show that pure pleasures are 
always true ones and vice versa." While it is true that Socrates proceeds to make the latter observation with regard to pure and true pleasures, it is not so clear that he does not see a difference between the two. Andrew McLaughlin argues for such a definite distinction by noting the importance context plays when determining whether a pleasure is true or false. He harks back to the fact that pleasures like opinions have supervening qualities which make them true or false. Their truth or falsity cannot be judged in isolation from the circumstances surrounding their occurence. Thus, if they are excluded from the good life it is not because they are mixed with pain but simply because they are false.

Nevertheless, while this distinction is cogent, it still seems that indeed mixed pleasures are false and that false pleasures are mixed. Mixed pleasures are always false pleasures for we have already seen that it is impossible to properly judge the degree of a pleasure or pain due to the fact that pleasure and pain belong to the Limitless and thus do not of themselves make a unit. False pleasures are always mixed because pleasure can never be separated from context, and, if the context is other than one thinks it, one is necessarily pained by a discontinutty of relation with reality even if one is not aware of that discontinuity.

similarly, we have already seen that true pleasures are unmixed. But we have not yet seen that all unmixed pleasures are true. This is easily discerned once we realize that what characterizes all of the pure pleasures noted above is that they have due measure: they are the pleasures of the temperate and have thoughtfulness involved in their accomplishment. Because of this, they are likewise true pleasures because they can be known for what they are and measured." This leads us into a transition in the dialogue that shows the parallel between true and false pleasures and mixed and unmixed pleasures.

The section which we are now entering may be divided into three parts. The first part makes the point that pure pleasures are, as we have said, characterized by due measure. Socrates makes the point that the more intense the pleasure, the more it is mixed with its opposite, pain $(52 \mathrm{c}-\mathrm{d})$. Thus, bulk or intensity cannot serve as the criterion of truth in pleasure, but rather measure or moderation is the essential attribute of true pleasure. Yet, since pleasure belongs to the Limitless, something must be added to it in order to give it measure and make it true." In the second part, we discover that the pure pleasures, because they are pure, are also true.s2 Socrates uses the example of whiteness to show this, saying that the purest whiteness is also the truest (52e-53a). At the conclusion of his examination of whiteness, he says that we, " are now in a position to realize that any and every 
sort of pleasure that is pure of pain will be pleasanter, truer, and fairer than one that is not, whatever be their comparative bulk or quantity" (53b-c). The third part consists in an argument stemming from the premise that pleasure consists in a continual process of generation, having no stable being. Socrates begins by noting that some things exist with a view to something else while others are those for which the first exist. Now, it is becoming which is for the sake of being, just as it is the art of shipbuilding which is for the sake of the ship. But since pleasure is a becoming, it must come to be for the sake of something else. Now in the relationship of means to end, it is the end which falls under the heading of good while the means falls under some other heading. "Thus, pleasure must fall under a heading other than the good and cannot be identified as the good (53b-54d). But the argument does not end here. Socrates goes on to note that the opposite of becoming is passing away and that it is therefore the alternation of passing away and becoming which is chosen by one who choses a life of pleasure in preference to a life of the purest possible activity of thought (55a).

Hackforth finds this third section coming at this point in the discussion to be somewhat perplexing, for he feels that it denies the association of good with pleasure in any way and goes beyond saying that pleasure is not the sole or chief good. This seems, says Hackforth, to go against earlier statements in the dialogue at $13 \mathrm{~b}$ and $28 \mathrm{a}$ which indicate that some pleasures ought to be admitted to the good life. Moreover, it goes against the later affirmation that certain pleasures are to be admitted to the good life. How to explain this?

Hackforth offers as one solution the fact that the conclusion is only provisional since the initial premise is conditional. He explains that Socrates develops such an argument for two reasons. First, he points out that the doctrine that pleasure is a becoming was one current at the time and could not be ignored in any discussion concerning pleasure. Secondly, he says that it is an argument whose conclusion is less antihedonistic when it is considered only provisionally."s

A second possible solution suggests itself when Klein argues that the purpose of the argument is to ask whether being is for the sake of becoming or becoming for the sake of being." since pleasure is limitless and thoughtfulness has limit, pleasure is becoming while thoughtfulness simply is, and pleasure is thus for the sake of thoughtfulness. If one would interpret the passage this way. I think it is possible to argue that pleasure is not dismissed but rather assigned its proper position. 
After an appeal to common sense against the view that one is better or worse depending on the degree of intensity to which he experiences pleasure or pain, 55 Socrates turns to an examination of nous and knowledge in order that he might discover the truest element in them, compare it to the truest element in pleasure, and come to the best decision with regard to which ought to receive the second prize (55a). He begins a process of division, dividing knowledge into that which produces things and that which serves education and nurture. He then divides productive knowledge into precise and imprecise knowledge. To precise productive arts he assigns measure and counting and says that they are superior to the imprecise productive arts. He then dism tinguishes between precise productive arts in which the measuring and counting deal with visible, tangible units and those which deal with entities that cannot be sensed. This latter class includes geometry and is the realm of the philosopher. Moreover, it is not for the sake of production and trade but rather for that of education and nurture." 6 Protarchus shows the importance of this last class by saying ". . . let our statement be that the arts which we have had before us are superior to all others, and that those among them which involve the effort of the true philosopher are, in their use of measure and number, immensely superior in point of exactness and truth.. . " (57c-d).

However, beyond pure mathematical knowledge there lies the power of dialectic which has its primacy in the fact that it deals with True Being, with that Being which always and immutably is.57 Protarchus raises the objection that he has heard elsewhere that rhetoric rather than dialectic is the greatest art since it has the power to subjugate all things by their own submission rather than by violence. Socrates replies that they are searching for the art or form of knowledge which devotes most attention to precision, exactness, and the fullest truth rather than for that which is greatest otherwise $(58 b-c)$. What one must ask is whether there is a power in the soul which is in love with Truth and acts for the sake of Truth. Acknowledging that there is such a power, one must concede that it possesses thoughtfulness and nous in their greatest purity. But to be in love with Truth is not the same as possessing it. Rather, such love involves the pursuit of Truth, and such pursuit involves submission to the power of discourse,". . . a power that is able to discover in the spoken or silent words that which makes speaking and thinking ultimately possible, namely the unchangeable and, thereby, true beings."

The majority of other arts deal with opinion, and those who consider themselves students of reality spend their time studying the corporeal universe, which comes 
to be and passes away. They therefore are not concerned with that which always is but rather with that which is becoming. Truth, however, does not attach itself to that which is subject to change. Such things can never be permanently grasped. Thus, nous and thoughtfulness, or phronesis, are not attached to changing opinion either, since they are the givers of perfect truth $(59 a-b)$. Socrates concludes, "[t/hat we find fixity, purity, truth, and what we have called perfect clarity, either in those things that are always, unchanged, unaltered, and free of all admixture, or in what is most akin to them; everything else must be called inferior and of secondary importance . . ." (59c).

The purpose of what has been surveyed thus far has been to set the stage for determining whether pleasure or thoughtfulness is most akin to the good life. We have found that it is in the well-mixed life that goodness is to be found. It is to be found in the wellmixed life not as an ingredient but as the form of the mixture itself.s" In other words, it actually constitutes the mixture as well-mixed. We have also isolated the purest pleasures and the purest form of thoughtfudness and nous, that which deals with True Being. By seeing how these two are properly mixed, we discover both the goodness in the good life and who is to receive the second prize.

To this end, we need to ask ourselves "what precisely is to be included in our mixture?" Socrates begins by noting how absurd it would be if only the purest forms of thoughtfulness were admitted--one could not cope with everyday situations and could not then be happy. All forms of nous and phronēsis must be admitted (62c-d). This is important for it points out that we are discussing the good life for the human. In the Phaedo, it will be remembered, Socrates excluded pleasure from the good life, but the pleasure he excluded was of an inferior sort. Here, by noting that all forms of thoughtfulness must be admitted to the good life, even the impure ones, he is able to move beyond asking if certain pleasures should be admitted to asking what pleasures should be admitted. He is recognizing, in other words, that the good human life because it is the human life necessarily involves pleasure in its mixture just as it necessarily involves knowledge of becoming in its mixture. Thus, true pleasures and necessary ones as well must be admitted to the mixture (62e). But should all pleasure be admitted? Socrates answers that all forms of nous and thoughtfulness are agreeable to pleasure ( $63 \overline{b-c})$, but is it the case that all of the various pleasures are agreeable to nous and thoughtfulness? This, in fact, is not the case, for in reply to Socrates' query as to whether all pleasures should be admitted to the good life is the contention that it would be senseless to 
mix with nous those pleasures which madden men's souls and are in other ways contrary to virtue." Intense pleasures serve only as obstacles to nous, while true and necessary pleasures are in accord with it. Protarchus agrees (63d-64a).

We have now come to view the mixture of the good life and are in a position to ask to whom the second prize belongs. But Klein asks us first to turn to a consideration of nous and phronēsis. In 64a Socrates drops phronēsis and says only that it would be senseless to mix pleasure with nous. Klein asks what nous this is. Is this the divine nous mentioned earlier? No, it is Socrates' own nous, for Socrates is answering guided by his own nous, says klein. It is Socrates' nous which is responsible for the kind of mixture that results in a life combining thoughtfulness and pleasure. This nous is the cause neither of the first two tribes nor of their commixture. Nous for socrates, according to Klein, is above all a human possession. The original reference to it as the cause of all and the subsequent limitation of it to the human realm is merely an attack on certain doctrines raised by Aristotle at the time."

It seems to me that Klein's assertion that Socrates' nous is responsible for the mixture of phronesis and nous with pleasure resulting in the good life serves to support rather than damage our initial contention that there is some sense in which nous plays the role of a distinctive cosmic cause. We have contended that the good life is a reflection of Reality just as we contain within ourselves the elements of earth, air, fire, and water found in the universe. Just as our nous is responsible for the mixture that composes the good life, so the cosmic nous is responsible for that mixture which is known as the Real. Socrates' statement in 64b concerning the need for Reality in order that the good life might exist seems to suggest this.

After Socrates makes his comment concerning Reality, he enters the final stage of the dialogue through his assertion that beauty, truth, and due measure give a mixture its goodness.6i Unless a mixture exhibits measure and proportion, it is no real mixture at all, but only". . . a miserable mass of unmixed messiness." Now, since the gualities of measure and proportion are constitutive of beauty and excellence, we can say as well that the goodness of the mixture takes refuge in beauty $(64 \mathrm{e})$. Socrates concludes:

Then if we cannot hunt down the good under a single form, let us secure it by the conjunction of three, beauty, proportion, and truth, and then, regarding these three as one, let us assert that that may most properly be held to determine the 
qualities of the mixture, and because that is good the mixture itself has become so. (65a).

At this point, we are in a position to ask whether nous or pleasure is more akin to that which constitutes the goodness of the mixture. In deciding this, we find which wins the second prize. We must therefore consider whether nous or pleasure is closer to beauty, proportion, and truth. With regard to truth, Protarchus readily agrees that pleasure is the greatest of imposters. He uses the example of love and says that for the pleasures of love even the gods forgive perjury. Reason, however, because it is identical with truth, is likewise the truest thing in the world. Again, with regard to proportion, Protarchus readily admits that pleasure is that which is most unmeasured in character (as we saw earlier, it is that which admits of the more and the less), while nous and phronesis are by nature the most measured. Lastly, Protarchus tells us that no one has ever had a vision of nous or phronēsis as ugly, nor can there ever be such a vision. But, with respect to pleasure, there is always an element of the ridiculous or of the ugly apprehensible, especially as regards the greatest pleasures (65c066a).

At last, Socrates is able to set down a list of possessions, with a given hierarchy to be assigned to the good life. Measure is the first of all possessions. The second lies in the region of what is proportional and beautiful. Reason and intelligence occupy the third realm, while the fourth consists of that which belongs to the soul itself, namely, the sciences, the arts, and right opinion. These are more akin to the good than pleasure. Finally comes the true pleasures, some of which attach to knowledge and others to sensation $(66 a-c)$.

But the dialogue has accomplished much more than arrive at this list; it has shown the inner workings of these five possessions and the profound relationship which exists between the good life and Reality. From what has been said, I think it is safe to conclude that what is most important in the dialogue foundationally is that there is first a unity and then a duality (not a plurality) which is yet a unity because of a certain interdependence. This duality is Limit and the Limitless. It is through the imposition of Limit on the Limitless brought about through nous, whether nous be a principle inherent in these arche or the unity from which they in some way procede, that mixture arises. This mixture consists of the eide and is characterized by number, measure, proportion. Indeed, the eidē are right number, right measure, right proportion, and it is in imitation of right number, measure, and proportion ranging throughout the universe that the good life derives its goodness. In other words, the 
good life is good becauge it reflects numbers, measure and proportion, which together constitute the Being of Reality.

\section{NOTES}

'Plato, Phaedo, trans. F. J. Church (Indianapolis: Bobbs-Merrill Company, Inc., 1951), 81.

'Plato, Philebus, trans. $R$. Hackforth in The Collected Dialogues of Plato, ed. Edith Hamilton and Huntington Cairns (Princeton: Princeton University Press, 1973), 11b-c (Here after cited in text).

'R. Hackforth, Plato's Examination of Pleasure (New York: The Bobbs-Merrill Company, Inc., 1045), p. 12 .

"Jacob Klein, "About Plato's Philebus", In Interpretation, vol. 2 , p. 159.

sMarsillio Ficino, The Philebus Commentary, trans. Michale J. B. Allen (Los Angeles: University of California, 1975), p. 280.

'Hackforth, p. 12 .

'Klein, p. 160.

Hackforth, p. 16n.

Ibid.

${ }^{10}$ Klein, p. 161.

"Ibid.

12 Ibid.

'Hackforth, pp. 18,20.

"Ibid., pp. 20-21.

${ }^{18}$ Klein, p. 162 .

1*Ibid., p. 167.

'Hackforth, p. 24.

"Ibid., pp. 20-21.

${ }^{9} \mathrm{Klein,} \mathrm{pp.} \mathrm{163,} 164$. 
${ }^{20}$ Hackforth, pp. 5, 32, 36 .

'Ibid., p. 36.

${ }^{22}$ Klein, p. 165.

${ }^{23}$ Ibid. , p. 166.

2"Ibid.

25 Ibid. , p. 168.

2 Ibid.

27 Ibid.

2*Ibid.

2"G. C. Field, The Philosophy of Plato (New York: Oxford Univesity Press, 1969), p. 90 .

${ }^{3}$ Hackforth, pp. 49-50.

'Klein, p. 169.

${ }^{2}$ Eicino, p. 418.

${ }^{3}$ Damascius, Lectures on the Philebus, trans. L. G. Wasterink (Amsterdam: North-Holland Publishing Co.. 1959), p. 48.

${ }^{24}$ Klein, p. 181.

"Constantin Ritter, The Essence of Plato's Philosophy, trans. Adam Alles (New York: The Dial Press, 1933), p. 197.

"Ibid., p. 198.

${ }^{3}$ Klein, p. 170 .

"Ibid. , p. 171 .

'Hackforth, pp. 58, 59, 61 .

"Andrew McLaughlin, "A Note on False Pleasures in the Philebus", in Philosophical Quarterly, vol. 19, 1969, P. 58.

'Hackforth, p. 69.

"Terry Penner, "False Anticipatory Pleasures: Philebus 36a3-41a6", in Phronēsis, vol. 15, no. 2, 1970. 
"Hackforth, pp. 77-78.

"tibid. , P. 78.

${ }^{4}$ McLaughlin, pp. 57-61.

"Klein, p. 176.

"Hackforth, pp. 98-99.

". Ibid., p. 99.

"Ibid., p. 102.

${ }^{\circ} \mathrm{K} l e i n$, p. 177.

"Hackforth, p. 102.

${ }^{32}$ Klein, p. 177 .

sHackforth, p. 107.

"Klein, P. 177.

${ }^{85}$ Hackforth, p. 111.

${ }^{s}$ Klein, p. 178.

' Ibid.

"Ibid., pp. 178-179.

s'Hackforth, pp. 122-123.

${ }^{\circ}$ Klein, p. 181.

'Ibid., pp. 181-182.

${ }^{\circ}$ Ibid., p. 182. 